\title{
PENERAPAN E-LEARNING SEBAGAI MEDIA PEMBELAJARAN DALAM MENGHADAPI PAMDEMI COVID -19
}

\author{
Devia Kartika1, Hezy Kurnia² \\ ${ }^{12}$ Universitas Putra Indonesia YPTK Padang, Indonesia \\ e-mail : devia.kartika11@gmail.com hezykurnia@gmail.com²
}

\begin{abstract}
Abstrak: Saat pandemi covid-19 seperti ini, mengakibatkan proses pembelajaran tatap muka langsung di kelas tidak mungkin dilakukan. Maka sangat perlu dibuatkan sistem pembelajaran jarak jauh atau sistem daring. Namun pelaksanaan pembelajaran pada pendidikan di SD Yayasan Dar El Iman - Padang ini masih mengalami berbagai kendala dengan sistem pendidikan yang konvesional yaitu tersedianya ruang komunikasi yang sangat terbatas dalam menjalankan proses belajar-mengajar dan melaksanakan PBM daring hanya dengan menggunakan aplikasi Whatsapp, sehingga diperlukan pemanfaatan teknologi secara optimal dalam menunjang pelaksanaan pendidikan dan peningkatan mutu pendidikan. Salah satu bentuk pemanfaatan teknologi dalam pendidikan adalah dengan penerapan pembelajaran secara online yaitu dengan konsep e-learning. Konsep yang dikenal dengan sebutan e-learning ini membawa pengaruh terjadinya proses transformasi pendidikan konvesional ke bentuk digital, baik secara isi dan sistemnya. Dalam kegiatan ini penulis melakukan metode pelatihan, demonstrasi, praktik dan pendampingan dalam penerapan e-learning yaitu menggunakan google classroom sebagai media pembelajaran. Dengan adanya e-learning ini diharapkan dapat meningkatkan keefektifan, pemahaman serta pengetahuan dan ketarampilan guru dalam menggunakan sistem pembelajaran online pada sekolah SD Yayasan Dar El Iman Padang.
\end{abstract}

\section{Kata Kunci: E-learning, Classroom, Daring}

Abstract: During the COVID-19 pandemic, it is impossible to do face-to-face learning in the classroom. So it is very necessary to make a distance learning system or an online system. However, the implementation of learning in education at the Dar El Iman Foundation Elementary School - Padang is still experiencing various obstacles with the conventional education system, namely the availability of very limited communication space in carrying out the teaching and learning process and implementing online PBM only by using the Whatsapp application, so the use of technology is needed. optimally in supporting the implementation of education and improving the quality of education. One form of using technology in education is the application of online learning, namely the concept of e-learning. This concept, known as e-learning, has the effect of transforming conventional education into digital form, both in terms of content and system. In this activity, the author conducts training, demonstration, practice and mentoring methods in the application of e-Learning. With this e-learning, it is hoped that it can increase the effectiveness, understanding and knowledge and skills of teachers in using online learning systems at the Dar El Iman Foundation Elementary School - Padang.

Keywords: E-learning, Classroom, Daring 


\section{Pendahuluan}

Pandemi Covid-19 telah merubah tatanan kehidupan masyarakat, tidak hanya menyerang negara Indonesia namun juga melanda dunia. Salah satu cara untuk memutus mata rantai penyebaran Covid-19 adalah dengan melakukan pembatasan interaksi masyarakat yang diterapkan dengan istilah physical distancing, Namun, kebijakan physical distancing tersebut dapat menghambat laju pertumbuhan dalam berbagai bidang kehidupan, baik bidang ekonomi, sosial, dan tentu saja pendidikan. Keputusan pemerintah untuk meliburkan para peserta didik, memindahkan proses belajar mengajar di sekolah menjadi di rumah dengan menerapkan kebijakan Work From Home (WFH) membuat resah banyak pihak .

Belajar dari rumah tentu berbeda dengan kegiatan belajar di sekolah, selain adanya perangkat pembelajaran kegiatan belajar juga didukung oleh media belajar untuk memudahkan siswa dalam memahami materi. Menurut Indriana (2011) media pembelajaran dimaksudkan merupakan salah satu alat komunikasi dalam proses pembelajaran, dikatakan demikian karena di dalam proses pembelajaran terdapat proses penyampaian pesan dari pendidik kepada anak didik. Dalam melakukan pembelajaran, pendidik mempunyai strategi masing-masing dalam menyampaikan materi ataupun ilmu kepada peserta didik.

Jadi, pembelajaran online yang diterapkan pada masa pandemi Covid19 merupakan strategi baru yang diterapkan untuk melanjutkan kegiatan belajar mengajar antara pendidik dan siswa yang dapat dilaksanakan dari rumah,. Pada pelaksanaannya siswa dan guru tidak perlu lagi melakukan kegiatan belajar mengajar secara tatap muka di ruang kelas, namun kini sudah bisa belajar dengan sistem pembelajaran online. Media online yang digunakan seperti youtube, whatsapp group, google classroom. Materi diberikan dalam bentuk powerpoint, video singkat, dan bahan bacaan.

Selama ini program pelaksanaan pendidikan di SD Yayasan Dar El Iman - Padang yang Jl. Gajah Mada Gang BPKP II No.Dalam, Kp. Olo, Kec. Nanggalo, Kota Padang, Sumatera Barat ini masih mengalami berbagai kendala dengan sistem pendidikan yang konvesional adalah tersedianya ruang komunikasi yang sangat terbatas dalam menjalankan proses belajar-mengajar, sehingga diperlukan pemanfaatan teknologi secara optimal dalam menunjang pelaksanaan pendidikan dan peningkatan mutu pendidikan. Salah satunya, dengan lahirnya konsep e-learning. Konsep yang dikenal dengan sebutan e-learning ini membawa pengaruh terjadinya proses transformasi pendidikan konvesional ke bentuk digital, baik secara isi dan sistemnya. Hal itulah yang mendasari penulis untuk melakukan penerapan E-Learning untuk pembelajaran guna meningkatkan keefektifan pembelajaran daring pada sekolah SD Yayasan Dar El Iman.

Beberapa Manfaat yang dapat diperoleh yaitu menerapkan pembelajaran ELearning, menerapkan strategi belajar dan metode pembelajaran inovatif yang menyenangkan bagi siswa dalam bentuk blended learning serta membantu dalam meningkatkan pemahaman dan pengetahuan guru serta ketarampilan guru dalam penerapan sistem pembelajaran online sesingga menarik daya tarik dan minat siswa untuk mengikuti pembelajaran.

\section{Metode}

Kegiatan Pengabdian Kepada Masyarakat (PKM) ini dilakukan dengan cara membagi pelaksanaan kegiatan penerapan pembelajaran secara online tentang 
menerapkan E-Learning pada SD Yayasan Dar El Iman . Implementasi Kegiatan dapat diuraikan sebagai berikut :

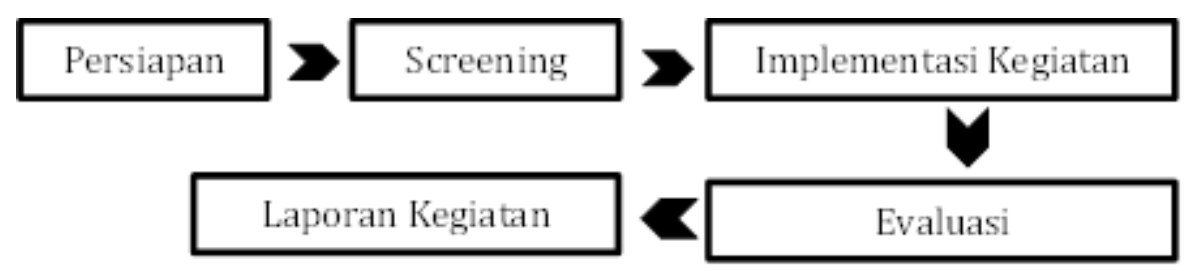

Gambar 1. Proses Implementasi Kegiatan

\section{1) Persiapan}

Persiapan dari kegiatan ini mencakup beberapa prosedur :

a. Menyiapkan materi

b. Survei lokasi

c. Mengurus surat-surat perizinan

d. Membuat proposal dan proses persetujuan lokasi pengabdian kepada masyarakat

\section{2) Screening}

Setelah memaksimalkan persiapan,screening kemudian menjadi agenda selanjutnya. Ada beberapa tahap yang dilakukan :

a. Menyiapkan bahan yang dibutuhkan dalam pengimplementasian E-Learning (Google Classroom) pada pembelajaran di SD Yayasan Dar El Iman .

b. Memastikan semua alat-alat siap di bawa ke lokasi

c. Memastikan semua kebutuhan acara seperti transportasi, konsumsi dan spanduk

\section{3) Implementasi Kegiatan}

a. Menyelenggarakan kegiatan dengan materi penyusunan laporan keuangan

b. Memberi pengetahuan tentang media pembelajaran yang lebih efektif secara online yaitu dengan E-Learning.

\section{4) Evaluasi}

Terlaksananya seluruh kegiatan PKM dengan lancar dan sukses

\section{5) Laporan Kegiatan}

Membuat laporan keseluruhan kegiatan.

\section{Hasil Dan Pembahasan}

Kegiatan akhir dari pelaksanaan pelatihan atau Pengabdian kepada masyarakat adalah melakukan evaluasi yang bertujuan untuk mengetahui sejauh mana kemampuan peserta meningkatkan pengetahuan dan keterampilannya dalam penerapan sistem pembelajaran online. Evaluasi ini dilakukan yaitu evaluasi pengetahuan dan keterampilan peserta dalam menggunakan Google Classroom sebagai media yang diberikan untuk 
melakukan mengajaran secara. Mulai dari pengenalan media E-learning hingga langsung menerapkan serta mempraktekan langsung.

Melalui evaluasi yang telah dilakukan, dapat diidentifikasi bahwa bimbingan praktis mengenai PKM penyusunan dan penerapan media pembelajaran e-learning memberikan hasil yang sangat memuaskan, karena peserta pelatihan tertarik dan bersungguhsungguh mengikuti kegiatan yang diberikan.Tingkat keberhasilan dan keterlaksanaan kegiatan PKM ini didasarkan pada antusias peserta pelatihan dan daya serap dari materi yang diberikan dan ditunjukkan dengan penyusunan perangkat pembelajaran dengan tepat.

Partisipasi peserta sangat tinggi, hal ini dilihat dari seluruh peserta mengikuti kegiatan pelatihan secara penuh waktu, peserta mempunyai motivasi dan antusias dalam memahami penyusunan media pembelajaran berbasis e-learning dengan mengguna- kan pendekatan-pendekatan sesuai dengan kompetensi dasar dan kompetensi inti, dan semua peserta aktif bertanya dan mengemukakan permasalahan-permasalah dalam menentukan arah dan tujuan yang diinginkan. Daya serap penguasaan materi oleh peserta baik dan ini terbukti pada saat diadakan praktik penerapan dan penyusunan pembelajaran berbasis elearning dan menjelaskan secara langsung. Dapat juga dilihat dari hasil kuisioner yang diisi oleh peserta pelatihan ini yang mana antusias peserta dapat diukur dari pertanyaan "Apakah Bapak/Ibu tertarik untuk mengikuti acara PKM yang akan kami selenggarakan?dan mengikuti kegiatan pelatihan lagi di lain waktu dengan tema/topik berbeda?" Jawaban yang diberikan Ya atau Tidak.

Dapat dilihat dari persentase dibawah ini ;

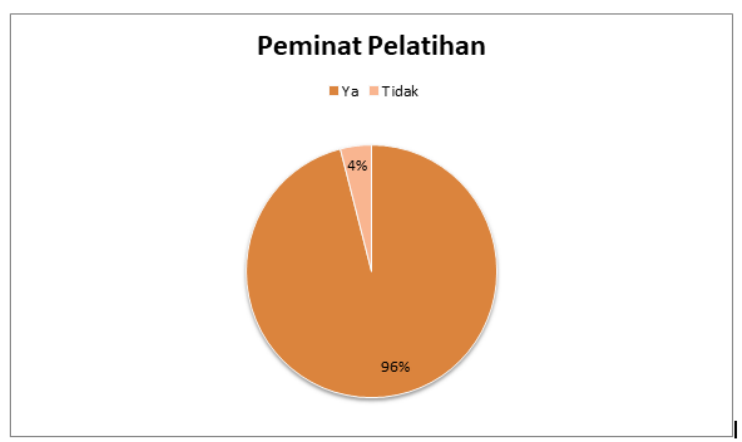

Grafik1. Persentase peserta yang Antusias dalam Pelatihan

Sehingga dapat diperoleh, dari 45 orang peserta dapat dilihat peminat pelatihan ini sekitar $96 \%$ yang tertarik dan antusian dalam kegiatan ini dan selebihnya sebanyak $4 \%$. Berikut tampilan beberapa kegiatan pelatihan pada Sekolah Dasar Darul El Iman. 

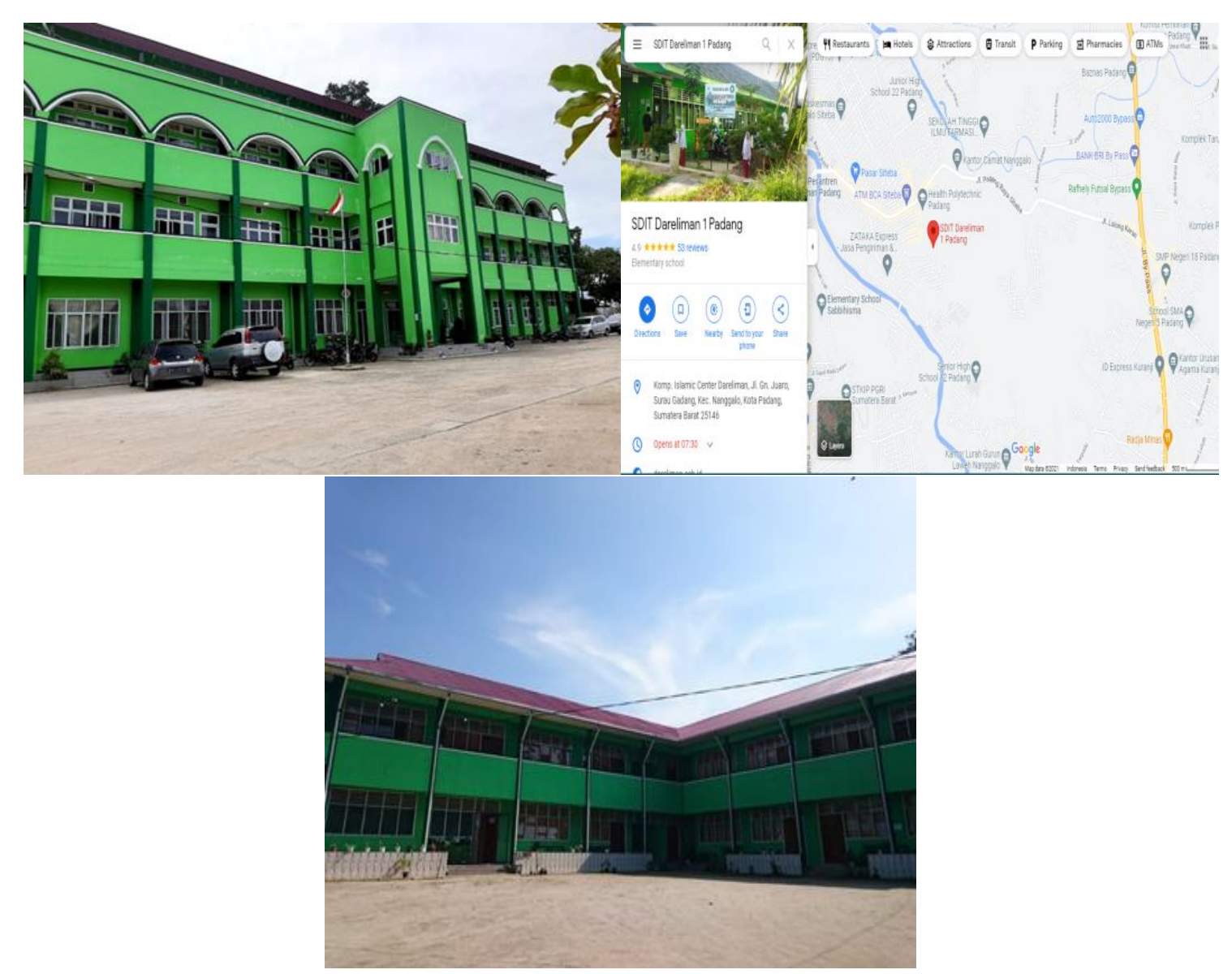

Gambar 2.Lokasi Kegiatan PKM (Sekolah Dasar Dar El Iman)

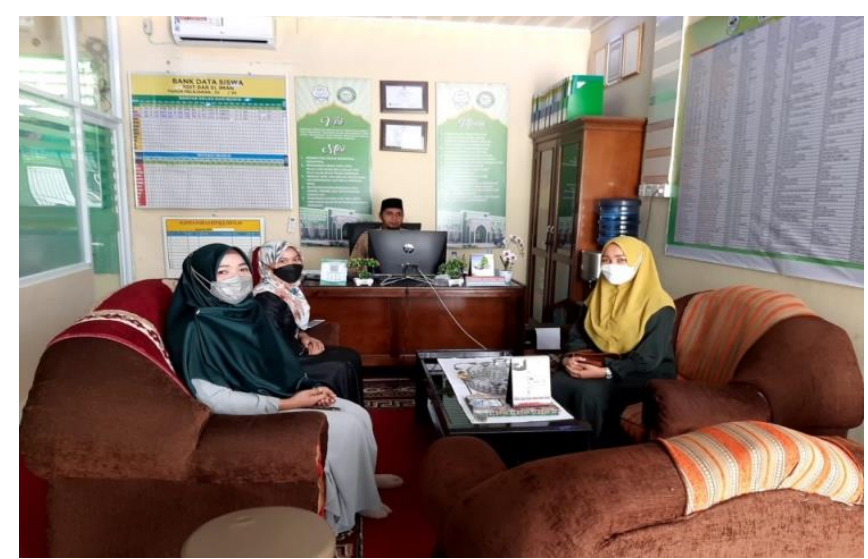

Gambar 3. Survey dan Diskusi dengan Kepala Sekolah 

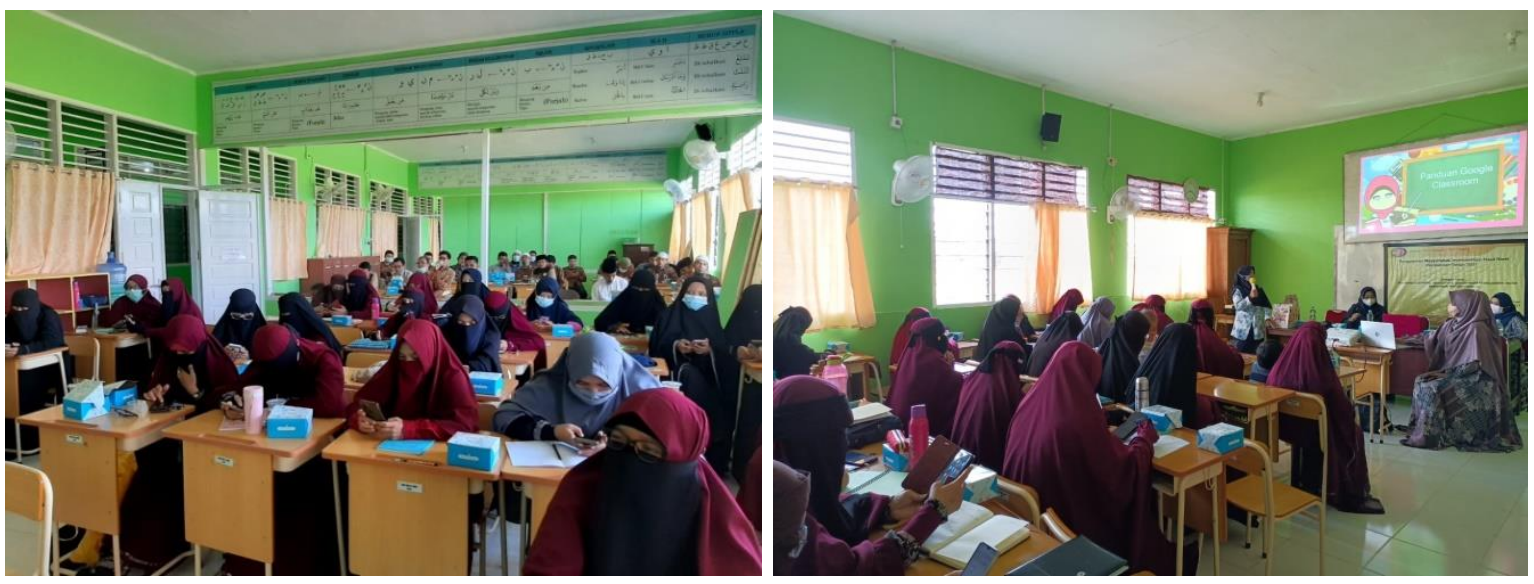

Gambar 4. Kegiatan Pengabdian Masyarakat

Dari dari hasil pelatihan tersebut pelaksana PKM juga membagikan kuisioner, Hasil yang didapatkan diantaranya yaitu seperti pada tabel 1. Kuisioner ini digunakan agar dari pelatihan yang diberikanan dapat memberikan manfaat dan sebuah perbaikan serta masukan agar kedepannya untuk pelaksanaan pengabdian lebih baik lagi.

Tabel 1. Hasil Kusioner Evaluasi Pelatihan E-Learning (Google Classroom) Sebagai Media Pembelajaran

\begin{tabular}{|c|c|c|c|c|c|}
\hline No & Pertanyaan Kuisioner & $\begin{array}{l}\text { Sangat } \\
\text { Tidak } \\
\text { Sesuai ( } \\
\text { STS ) } \\
\end{array}$ & $\begin{array}{l}\text { Tidak } \\
\text { Sesuai } \\
\text { (TS) }\end{array}$ & $\begin{array}{l}\text { Sesu } \\
\text { ai (S) }\end{array}$ & $\begin{array}{l}\text { Sangat } \\
\text { Sesuai } \\
\text { SS }\end{array}$ \\
\hline 1 & $\begin{array}{l}\text { Bagaimana Pendapat Bapak/Ibu } \\
\text { mengenai Waktu Pelaksanaan PKM? }\end{array}$ & $2,2 \%$ & $2,2 \%$ & $\begin{array}{l}13,33 \\
\%\end{array}$ & $82,2 \%$ \\
\hline 2 & $\begin{array}{l}\text { Bagaimana Pendapat Bapak/Ibu } \\
\text { mengenai kesesuaian Tema dengan } \\
\text { Materi yang disampaikan pada PKM? }\end{array}$ & - & 4,44 & $\begin{array}{l}6,67 \\
\%\end{array}$ & $88,88 \%$ \\
\hline 3 & $\begin{array}{l}\text { Bagaimana pendapat Bapak/Ibu } \\
\text { mengenai Penyampaian Materi dari } \\
\text { Narasumber? }\end{array}$ & - & 2,22 & $\begin{array}{l}24,44 \\
\%\end{array}$ & $73,33 \%$ \\
\hline 4 & $\begin{array}{l}\text { Bagaimana pendapat Bapak/Ibu } \\
\text { mengenai Penyampaian Moderator? }\end{array}$ & - & - & $29 \%$ & $71 \%$ \\
\hline 5 & $\begin{array}{l}\text { Apakah acara ini bermanfaat bagi } \\
\text { Bapak/Ibu Peserta PKM? }\end{array}$ & - & - & $16 \%$ & $84 \%$ \\
\hline 6 & $\begin{array}{l}\text { Bagaimana pendapat Bapak/Ibu terhadap } \\
\text { keseluruhan acara PKM ini? }\end{array}$ & - & - & $22 \%$ & $78 \%$ \\
\hline
\end{tabular}

Berdasarkan pada table 1jumlah responden yang mengisi yaitu 45 orang dengan hasil persentase yang diperoleh yaitu terkait Waktu Pelaksanaan PKM menghasilkan 82,2 $\%$ yang menjawab sangat sesuai, 13,33 \% menjawab sesuai, 2,2\% menjawab tidak sesuai dan $2,2 \%$ menjawab sangat tidak sesuai. Hal ini menandakan pelatihan yang 
dilakukan sesuai dengan waktu yang di berikan. Terkait dengan kesesuaian Tema dengan Materi yang disampaikan dapat dilihat 88,8 \% yang menjawab sangat sesuai, $6,67 \%$ menjawab sesuai dan 4,44\% menajwab tidak sesuai. Hal ini menandakan apa yang diharapkan peserta terkait dengan permasalahan untuk diselesaikan. Dan untuk keterangan lainnya dapat dilihat dari grafik di bawah ini;

1. Waktu Pelaksanaan

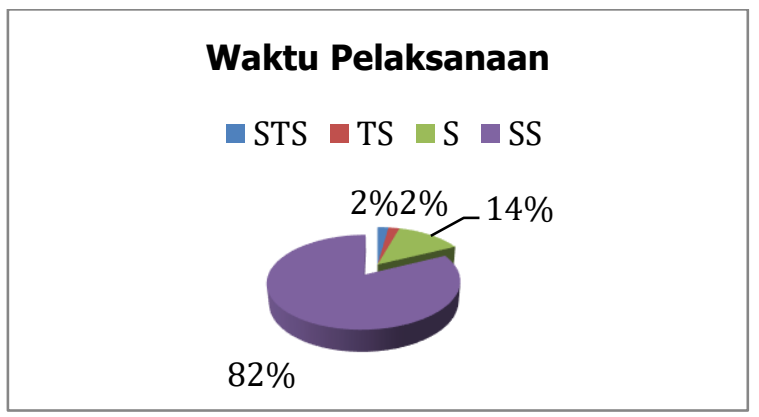

Grafik 2. Persentase Waktu pelaksanaan sesuai kebutuhan

2. Kesesuai tema dengan materi yang disampaikan

\section{Kesesuaian Tema dengan Materi yang disampaikan}
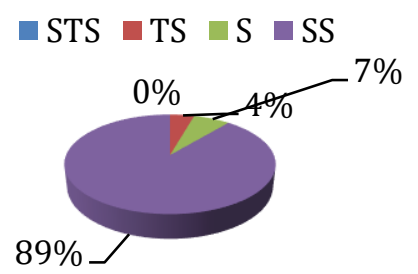

Grafik 3. Persentase Kesesuaian Tema dengan Materi yang disampaikan

3. Penyampaian Materi dari Narasumber

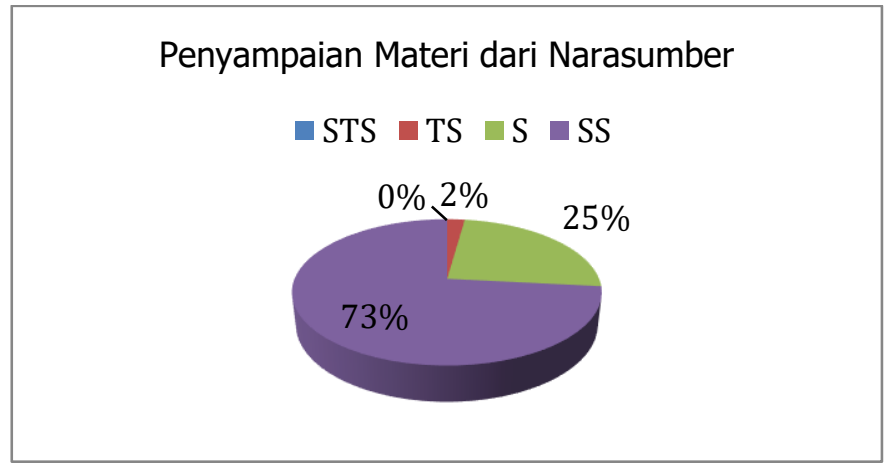

Grafik 4. Persentase Penyampaian Materi dari Narasumber 
4. Penyampaian Moderator

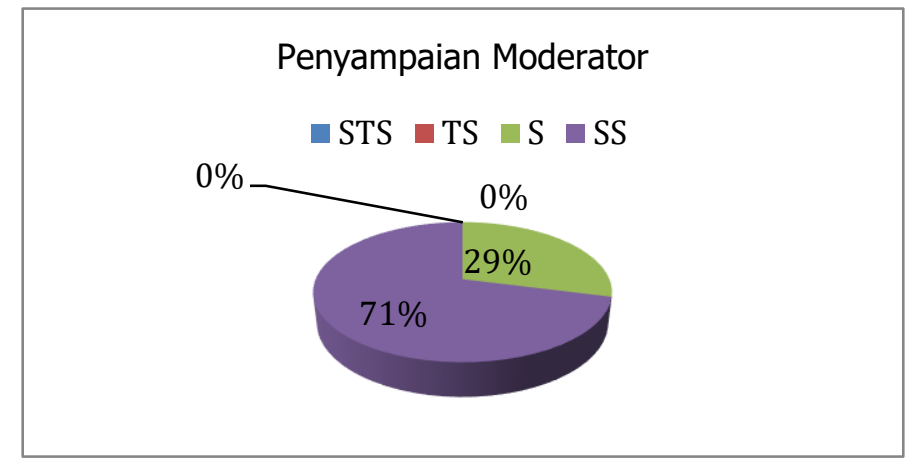

Grafik 5.Persentase Penyampaian Moderator

5. Manfaat Kegiatan

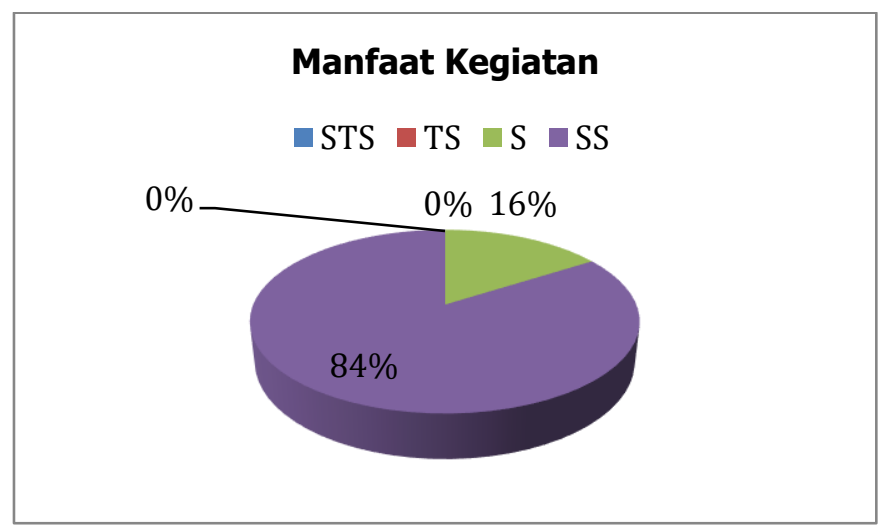

Grafik 6. Persentase Manfaat Kegiatan

6. Pendapat Peserta terhadap Kegiatan

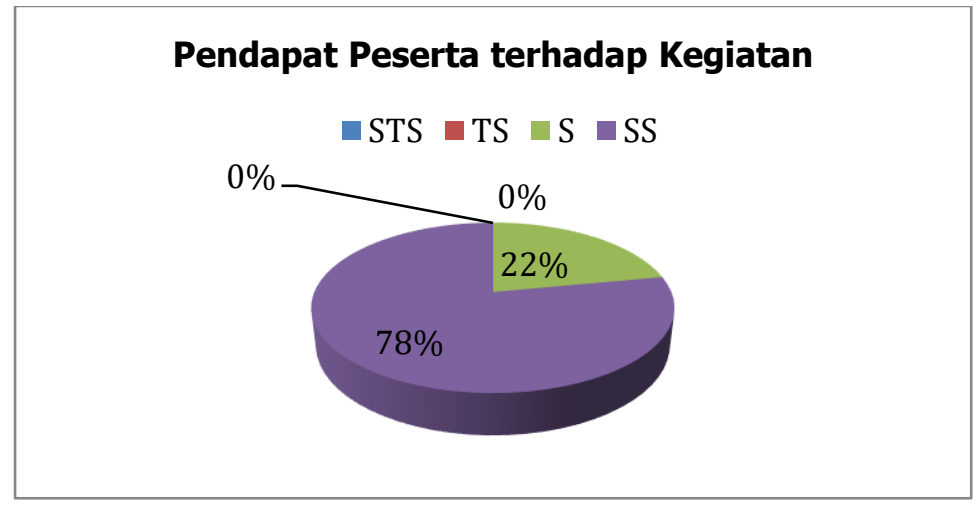

Grafik 7. Persentase Pendapat Peserta terhadap Kegiatan

Beberapa masukan yang disarankan oleh peserta selaian penilaian yang bersifat pilihan yaitu : 

a. Perlunya pendampingan kembali kedepannya dan Lebih intens lagi dengan peserta.
b. Materi yang disampaikan lebih teratur dan melihat segmen peserta, dikarenakan peserta ada yang belum memahami terkait materi
c. Perlu waktu tambahan dikarenakan waktu yang singkat dalam pelatihan
d. Kedepannya ada pelatihan dengan tema lainnya

\section{Kesimpulan}

Berdasarkan Kegiatan Pengabdian Masyarakat yang telah dilakukan, dapat diambil kesimpulan sebagai berikut :

1. Dengan adanya penerapan E-Learning ini proses pembelajaran di SD Darel El-Iman dapat terlaksana dengan baik

2. Dengan E-learning ini proses penjadwalan pembelajaran, pelaksanakan pembelajaran sekaligus evaluasi pembelajaran dapat dilakukan dengan secara efektif dan efisien

3. Tampilan interface yang lebih baik dan mudah digunakan membuat Guru dan Siswa menjadi lebih nyaman dalam pelaksanaan sistem pembelajaran secara daring

4. Keterbatasan koneksi dan gangguan jaringan internet membuat Guru-guru maupun siswa SD Darel El Iman kesulitan dalam mengakses aplikasi E-Learning sehingga proses pembelajaran menjadi tertunda

\section{Ucapan Terima Kasih}

Tim pelaksana Pengabdian Masyarakat mengucapkan terima kasih kepada Bapak/Ibu Ketua Yayasan Universitas Putra Indonesia YPTK Padang yang telah mendanai Pengabdian Masyarakat dalam hibah Dosen Tahun pelaksanaan 2021. Terima kasih kepada Bapak Rektor, Pimpinan serta dosen dan pihak-pihak yang membantu dalam kegiatan pelaksanaan Pengabdian Masyarakat ini.

\section{DAFTAR PUSTAKA}

Doni Septumarsa Ibrahim, Siti Partini Suardiman. 2014 . Pengaruh Penggunaan ELearning Terhadap Motivasi Dan Prestasi Belajar Matematika Siswa Sd Negeri Tahunan Yogyakarta. Jurnal Prima Edukasia, Vol.2, No.1

Erianti, S., \& Adila, D. R. (2019). Penyuluhan Berbasis Multimedia dalam Mencegah Perilaku Seks pada Remaja di SMU Negeri 11 Pekanbaru. Jurnal Pengabdian Masyarakat Multidisiplin, 2(3), 214-220.

Indriana, Dina. 2011. Ragam Alat Bantu Media Pengajaran. Yogjakarta: DIVA Press

Julianto, V., Suprianto, A., Prastyaningsih, Y., \& Yuliyanti, W. (2021). Pelatihan Pembuatan Dan Pengelolaan Website Sekolah Sebagai Media Informasi Untuk Operator Sekolah Se-Kecamatan Batu Ampar. Jurnal WIDYA LAKSMI (Jurnal Pengabdian Kepada Masyarakat), 1(2), 62-67.

Mason, R \& Rannie, F. (2010). Elearning (Terjemahan Teguh Wahyu Utomo). New York: Tylor Francis. (Buku asli terbitan tahun 2009)

Moore, Alex. (2004). The good teacher: dominant discourses in teaching and teacher education. London and New York: Routledgefalmer 
Naidu, Som. (2006). E-learning: A guide book of principle, procedure and practice:

Bengali: Aishi Cretive Workshop

Nurkencana. (2005). Evaluasi hasil belajar mengajar. Surabaya: Usaha Nasional.

Peterson, J., Karen L., Pickering, M., \& Steven, H. (2006). A comparison of computerassisted instruction and field-based learning for youth range-land education. 